\title{
Article \\ Ferroelectric Behavior and Spectroscopic Properties of La-Modified Lead Titanate Nanoparticles Prepared by a Sol-Gel Method
}

\author{
M. Mostafa*1,2, Z.A. Alrowaili², G. M. Rashwan'1,3, M. K. Gerges ${ }^{3}$ \\ 1 Laser Tech. \& Environment Lab., Physics Department, Faculty of Science, South Valley University, Qena, \\ 83523 Egypt; masoud.mostafa@sci.svu.edu.eg \\ 2 Physics Department, College of Science, Jouf University, Sakaka, Saudi Arabia; mmostafa@ju.edu.sa \\ 3 Ferroelectric Lap, Physics Department, Faculty of science, South Valley University, Qena 83523, Egypt; \\ magic tota88@yahoo.com \\ * Correspondence: mmostafa@ju.edu.sa
}

\begin{abstract}
Perovskite type (Pb1-1.5x Lax $\sqsubset 0.5 \mathrm{x}$ )TiO3 (PLT) ceramics with $\mathrm{x}=0.21,0.22,0.23,0.24,0.25$ were prepared by the sol-gel method. Their structural, optical, and dielectric properties were investigated. The crystallite compounds were obtained by calcinating the mixture of $\mathrm{PbCO} 3, \mathrm{TiO} 2$, and $\mathrm{La} 2 \mathrm{O} 3$ at $1000^{\circ} \mathrm{C}$ for different time periods. After $4 \mathrm{~h}$ annealing, PLT23 sample, no secondary phases have been observed in the XRD spectrum of the PLT sample with 23\% La content (PLT23). This sample appears to be notably distinguished in its structural, optical, and dielectric characteristics compared with other samples.
\end{abstract}

Keywords: Ceramics, PLT, Sol-Gel, Optical, Dielectric Constant.

\section{Introduction}

Ferroelectric ceramics are important electronic materials that are widely applied in various industries, such as capacitors, transducers, sensors, and ultrasonic motors [1]. Perovskite systems (ABO3), a potential applicant as the ferroelectric materials, has attracted great research interests. The $\mathrm{B}$ site substitution of perovskite systems (ABO3) has been studied comprehensively [2,3]. Among all perovskite ferroelectric materials, lead titanate ( $\mathrm{PbTiO} 3$ or $\mathrm{PT}$ ) ceramics have been extensively investigated. The improvement in the piezoelectric and pyroelectric properties is achieved by replacing $\mathrm{Pb}$ in the $\mathrm{A}$ site of the $\mathrm{ABO} 3$ structure [4-6]. The prominent $\mathrm{PbTiO} 3$ with the perovskite crystal structure possesses a relatively high Curie point of $4900{ }^{\circ} \mathrm{C}$. The high c/a ratio in $\mathrm{PbTiO} 3$ at low temperature confers tetragonal phase. So it disintegrates into powder when cooled to the Curie point [7]. Some authors have already reported various methods of $\mathrm{PbTiO} 3$ nanopowder preparation, such as the conventional mixed-oxide method, Pechini-type processes, mechanochemical synthesis, hydrothermal process, sputtering, spray drying, and sol-gel processing [8-14]. Among these methods, the low-cost and simple sol-gel technique can precisely control the composition, making it more advantageous.

Lanthanum (La) - modified lead titanate (i.e., lead lanthanum titanate, PLT) is one of the important ferroelectric materials, which has excellent dielectric, ferroelectric, pyroelectric, and electro-optic properties. By doping $\mathrm{PbTiO} 3$ nanopowders with $\mathrm{La}$, the permittivity of the resulting PLT increases with Tc while its tetragonality decrease with increasing La content [15]. The coercive field required to polarize the ceramic drops, and a pyroelectric coefficient larger than that $\mathrm{PT}$ is observed [16]. Due to their excellent dielectric and piezoelectric properties [17-20], lead-based relaxor ferroelectrics with complex perovskite structure are widely used in multilayer capacitors, piezoelectric actuators, and ultrasonic transducers. In lanthanum containing lead titanate [21], La3+ ions occupy $\mathrm{Pb} 2+$ sites and generate vacancies $(\square)$ in the cation lattice of (Pb1-1.5x Lax , $\square 0.5 \mathrm{x}) \mathrm{TiO} 3$ 
ceramics. With increasing La3+ content, the transition temperature Tc decreases linearly. Experimental and theoretical studies on some ferroelectric properties of ceramics with previous chemical formula have been published [22], reporting that its behavior of dielectric peak $\varepsilon$ max is similar to that of single vacancies at the same La content. The highest value of $\varepsilon$ max at $x=0.2$ corresponds the maximum number of single vacancies, i.e., both the dielectric peak $\varepsilon$ max and the number of single vacancies are proportional to La content until the value reaches $20 \%$. Wu et al. [23] reported some data of the perovskite structure with the general formula $\mathrm{ABO} 3$ where the A site of vacancies reduces the local stress in the domains undergoing domain switching. The domain width is proportional to the grain size [24]. It has been observed in many studies [25-31] that the increase in grain size is associated with the increasing dielectric peak $\varepsilon$ max.

The present work aims to study the microstructural, optical, and dielectric properties of $\mathrm{PbTiO} 3$ with various La-doping concentrations (i.e., $x=0.21,0.22,0.23,0.24$, and, 0.25 mole La, denoted as PLT21, PLT22, PLT23, PLT24, and PLT25, respectively).

\section{Materials and Methods}

The (Pb1-1.5x Lax $\square 0.5 \mathrm{x}) \mathrm{TiO} 3$, where $(\mathrm{x}=0.21,0.22,0.23,0.24$, and 0.25 mole La) nano-particles were prepared by the sol-gel method. The raw materials used were commercially available lead carbonate $(\mathrm{PbCO} 3)$, titanium dioxide (TiO2), and lanthanum oxide ( $\mathrm{La} 2 \mathrm{O} 3)$, which were purchased from Alfa Aesar, a Johnson Matthey Co. Potassium hydroxide (KOH, 0.2 moles) was dissolved in 100 $\mathrm{ml}$ distilled water and 0.1 moles of $\mathrm{PbCO} 3$ was added to the prepared $\mathrm{KOH}$ solution. The mixture was magnetically stirred for 1 hour and then filtered. The solids retained on the filter was added to $100 \mathrm{ml}$ distilled water and 0.1 moles of TiO2. The resultant mixture was magnetically stirred for $2 \mathrm{~h}$. Then, the mixture powders were calcined at the calcination temperature of $1000{ }^{\circ} \mathrm{C}$, for 2 and $4 \mathrm{~h}$ at a heating/cooling rate of $5^{\circ} \mathrm{C} / \mathrm{min}$. X-ray diffraction (XRD) was employed to identify the phase formed. The particle morphology and size were directly imaged by transmission electron microscopy (TEM); the average particle size was determined using the Scherrer method. A pellet of $7 \mathrm{~mm}$ diameter and $1 \mathrm{~mm}$ thickness was prepared for the electrical properties study. Thin silver electrodes were screen printed onto the opposite face of the ceramic disk. For organic removal, the printed disks were kept on an alumina plate and first heated at $500^{\circ} \mathrm{C}$ for $2 \mathrm{~h}$. To measure its capacitance, the heated disk was then positioned between two copper electrodes that were connected to an automatic capacitance meter (RLC - meter model SRS) [32].

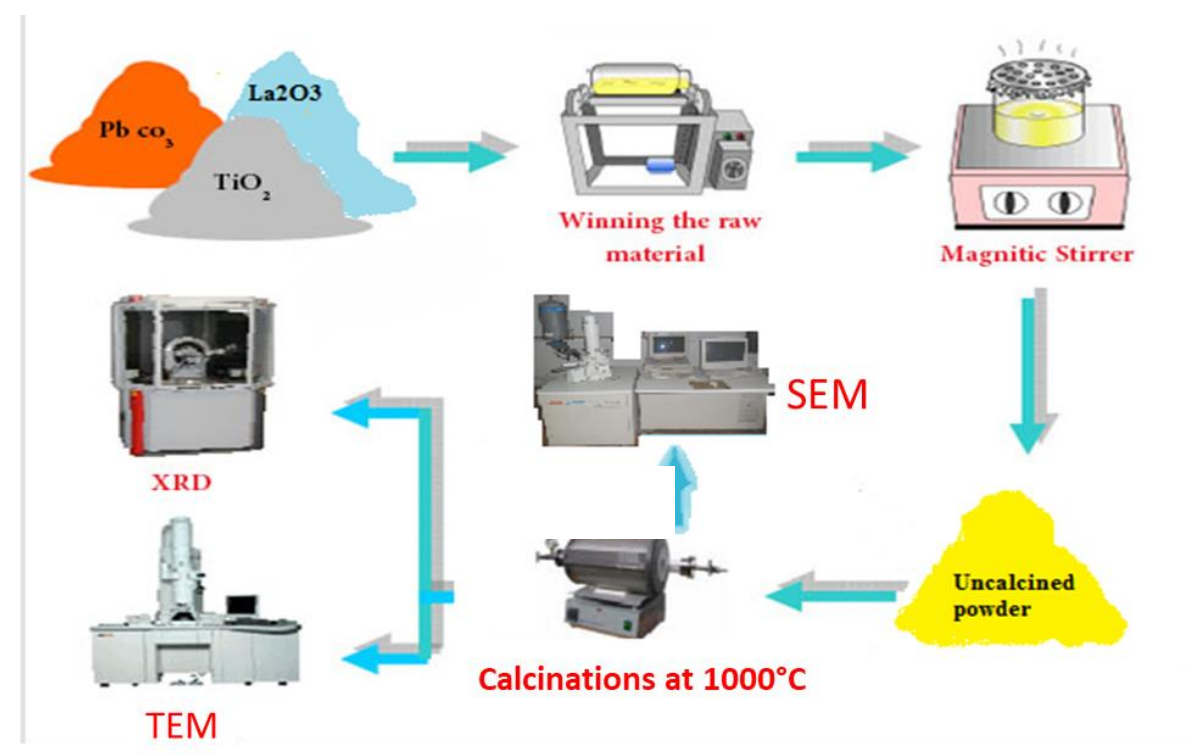

Figure 1. The block diagram of the sol-gel preparation method [14]. 


\section{Results and Discussion}

\subsection{X-ray diffraction:}

The XRD patterns were obtained for the powders calcined at $1000{ }^{\circ} \mathrm{C}$ using XRD (EMMA)

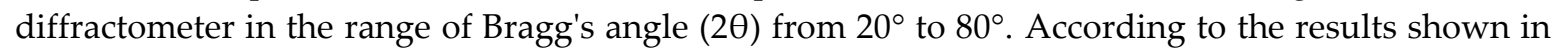
Figures 2 and 3, it is clear that, in the case of the sample calcined at $1000^{\circ} \mathrm{C}$ for $2 \mathrm{~h}$, crystallization started to form perovskite PLT phase along with small impurities of $\mathrm{PbO}$ and $\mathrm{TiO} 2$. However, the impurity phases gradually decreased when annealed at $1000{ }^{\circ} \mathrm{C}$ for a longer period of time. As a result, after $4 \mathrm{~h}$ of calcination, the TiO2 impurities disappeared in all PLT samples with La concentrations ranging from $21 \%$ to $25 \%$. The sample with $23 \%$ La sintered at $1000{ }^{\circ} \mathrm{C}$ for $4 \mathrm{~h}$ showed the highest purity. The sharp intensity peak at $2 \theta=31.85^{\circ}$ indicates the formation of perovskite PLT phase; while no peaks for the unwanted $\mathrm{TiO} 2$ or $\mathrm{PbO}$ phases are observed in the XRD patterns, indicating that the sol-gel process used in the present study is a suitable technique for the preparation of PLT nanoparticles. The broad XRD peaks suggest the presence of nanocrystalline particles. Based on these XRD patterns, the crystallite sizes were calculated using the Scherrer's formula:

$$
\mathrm{t}=0.9 \lambda / \beta \cos \theta
$$

where $\lambda$ is the wavelength, $\beta$ is the full width at half maximum (FWHM), and $\theta$ is the diffraction angle.

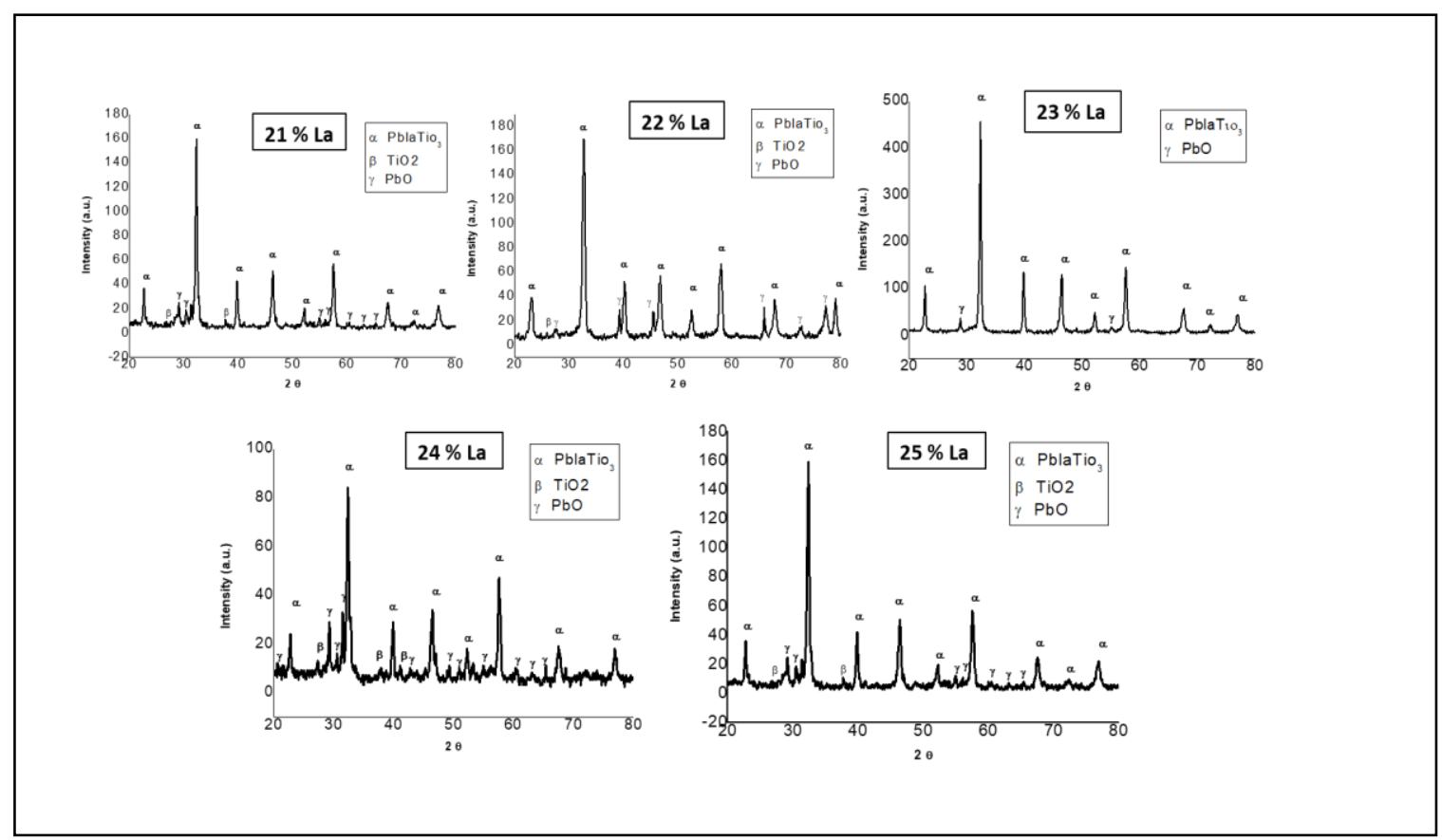

Figure 2. X-ray diffraction patterns of PLT ceramics annealed for $2 \mathrm{~h}$ at $1000^{\circ} \mathrm{C}$. 

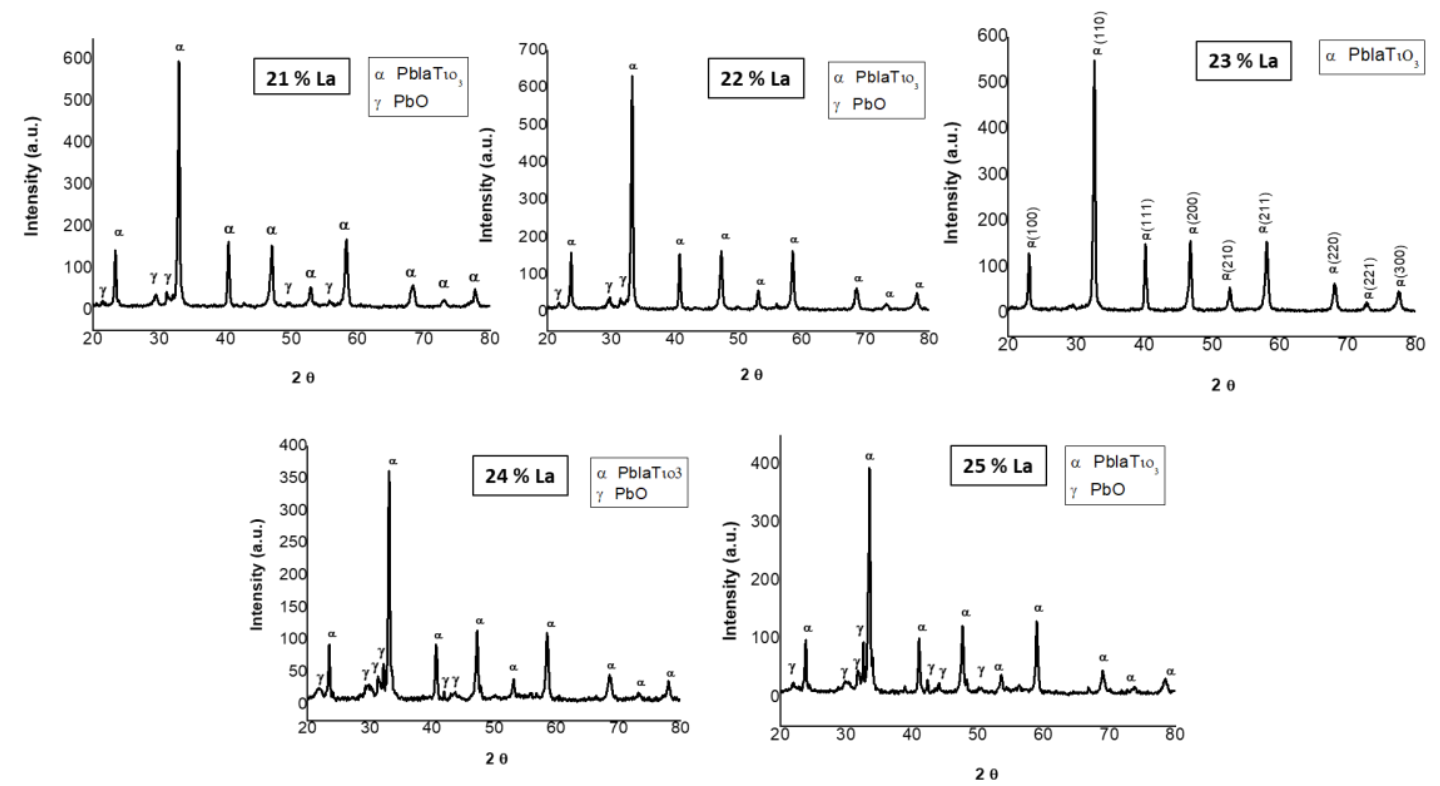

Figure $3 \mathrm{X}$-ray diffraction patterns of PLT ceramics annealed for $4 \mathrm{~h}$ at $1000^{\circ} \mathrm{C}$.

\subsection{SEM Analysis}

Figure 4 shows the morphology and size distribution PLT powders of 21, 22, 23,24 and $25 \%$ La, respectively. The particles are more or less spherical in their morphology. The individual particles observed in the SEM are expected to be polycrystalline and hence their size is larger than the crystallite size obtained from X-ray peak broadening. The particle size of the PLT was found to be maximum for the sample with $23 \%$ La dopant, which will be conformity with the XRD results. 

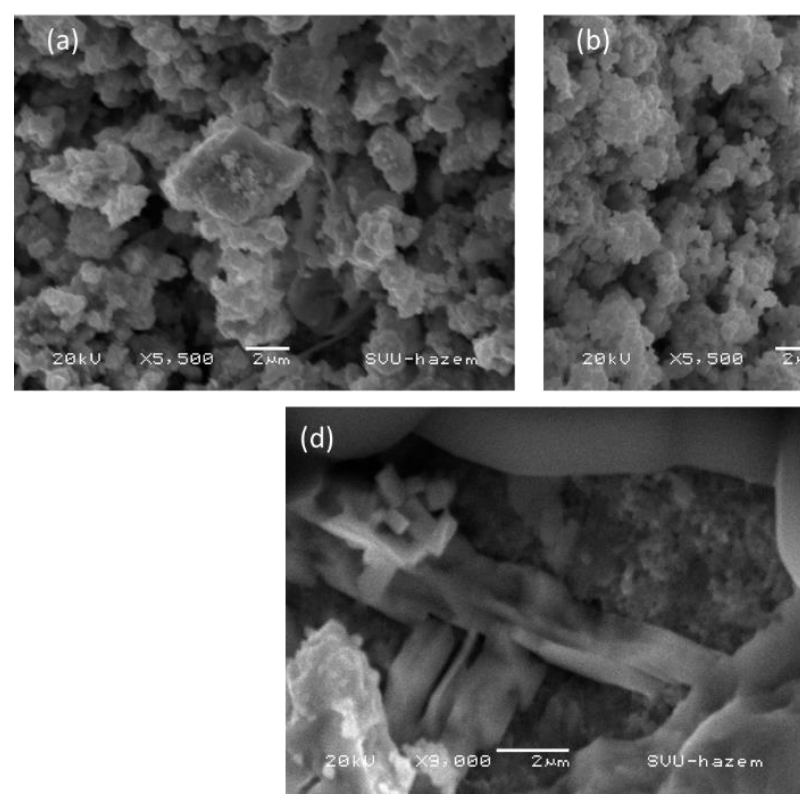
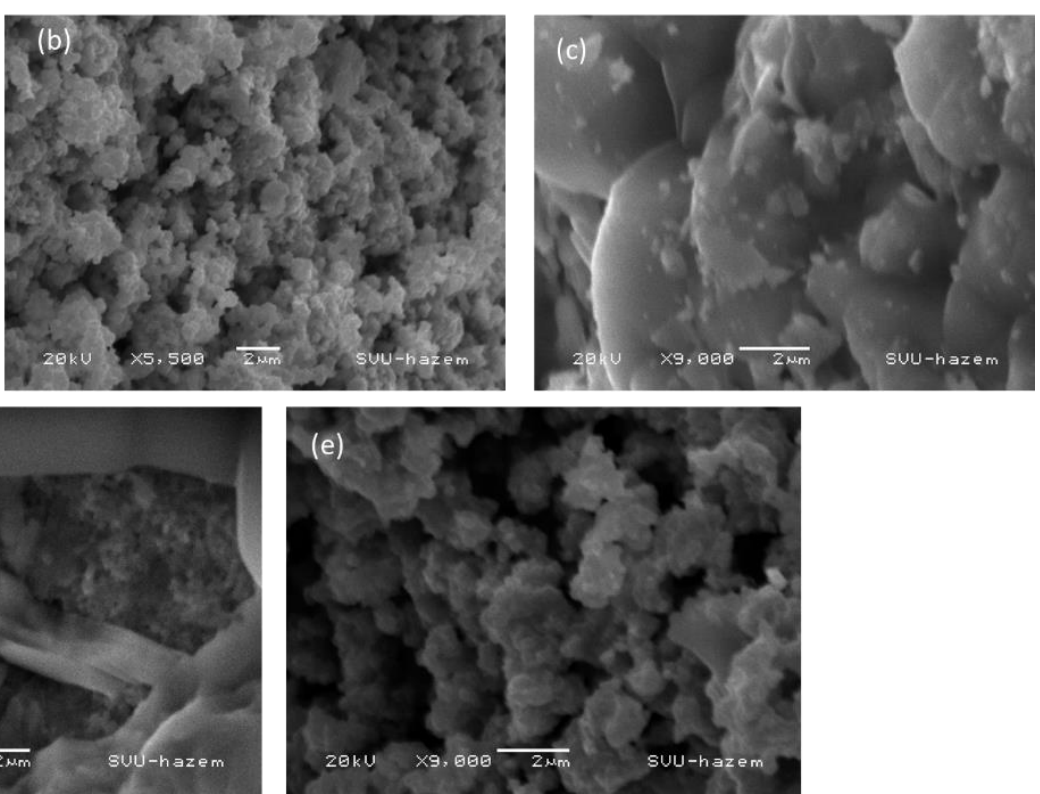

Figure 4. SEM images of $[(\mathrm{Pb} 1-\mathrm{x}$ Lax $\square 0.5 \mathrm{x})] \mathrm{TiO} 3$ ceramics sintered at $1000{ }^{\circ} \mathrm{C}: \mathrm{x}=$ (a) 0.21 , (b) 0.22 , (c) 0.23 , (d) 0.24 , and (e) 0.25 .

\subsection{TEM Analysis}

Figure 5 presents the typical TEM images of the PLT powders with different La contents calcined at $1000^{\circ} \mathrm{C}$. According to TEM images, the PLT powders were heterogeneous, which may be due to the agglomeration of particles during their preparation. The primary particle size of the powder was determined by TEM analysis.
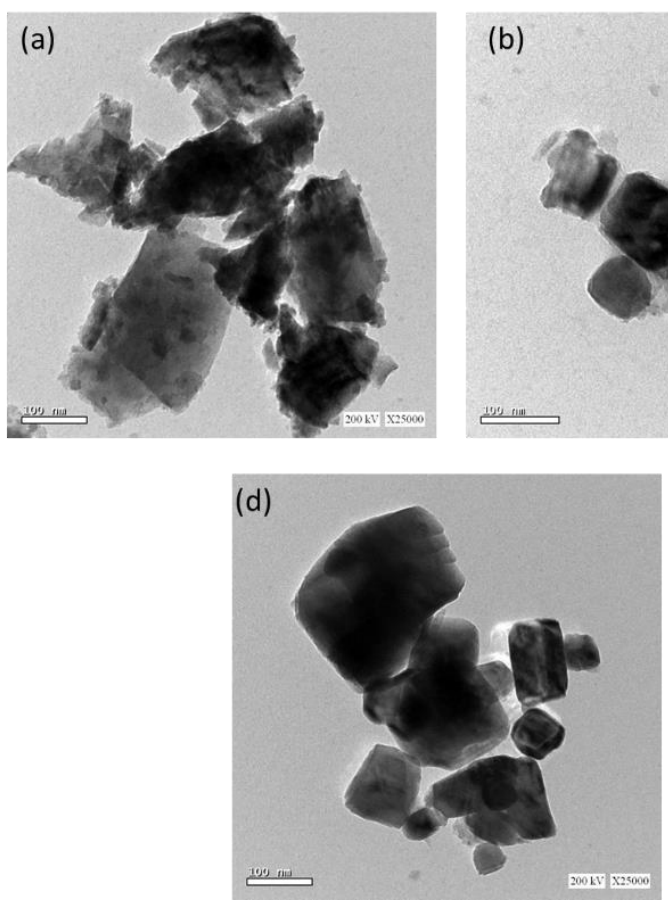

(b)

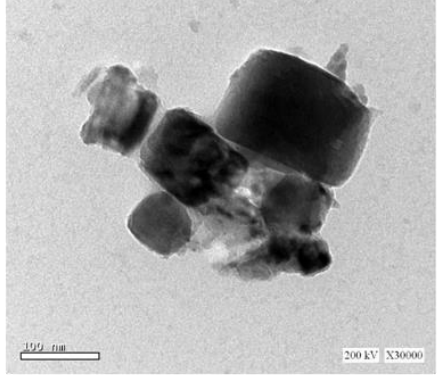

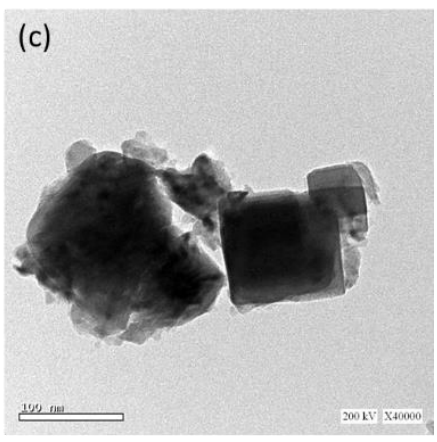

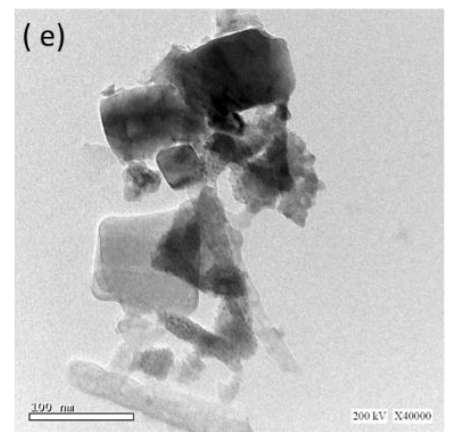

Figure 5. TEM images of $[(\mathrm{Pb} 1-\mathrm{x}$ Lax $\square 0.5 \mathrm{x})] \mathrm{TiO} 3$ ceramics sintered at $1000{ }^{\circ} \mathrm{C}: \mathrm{x}=(\mathrm{a}) 0.21$, (b) 0.22, (c) 0.23 , (d) 0.24 , and (e) 0.25 . 


\subsection{Optical properties}

The optical properties of the prepared nanoparticles were studied by a UV-Visible Spectrophotometer (UV-300II, TECHCOMP). Figure 5 presents the UV-Vis transmission spectra of the electrochemically synthesized nanoparticles in the 400-750 nm wavelength range at room temperature. The value of the optical gap Eg is calculated based on the Tauc plot [14]:

$$
\mathrm{h} v \alpha=(\mathrm{h} v-\text { Egopt }) 2
$$

where $\mathrm{h}$ is the Plank constant, $v$ is the frequency, and $\alpha$ is the optical bandgap. The PLT bandgap Eg can be estimated by plotting $(\alpha h v) 1 / 2$ versus $h v$ and extrapolating the linear portion of the plot to $(\alpha \mathrm{hv}) 1 / 2=0$ (as shown in Figure 7). The calculated bandgaps were 2.23, 3.24, 4.51, 2.61, and 2.28 for the PLT with $0.21,0.22,0.23,0.24$ and $0.25 \% \mathrm{La}$, respectively.

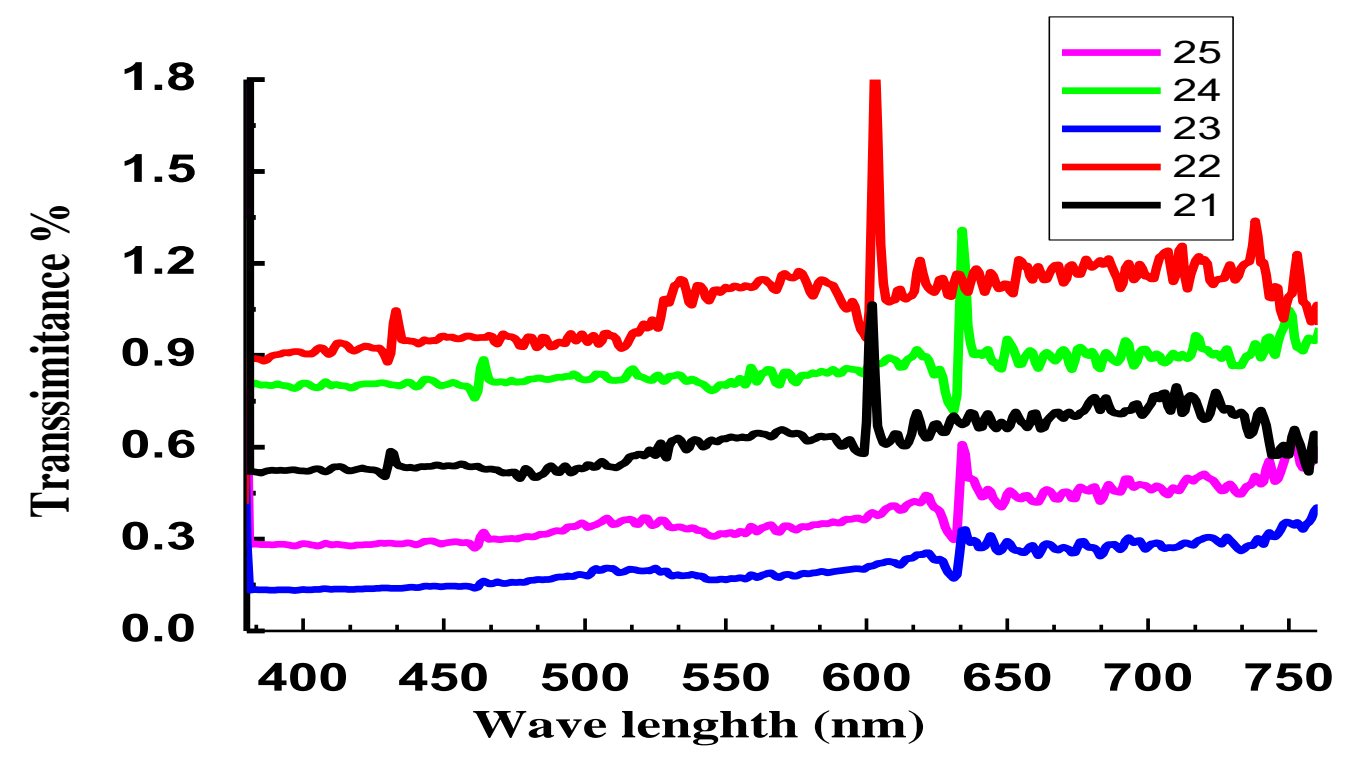

Figure 6. Transmittance spectra in the range of visible light of PLT powders with different La concentrations calcined at $1000^{\circ} \mathrm{C}$ for $2 \mathrm{~h}$.
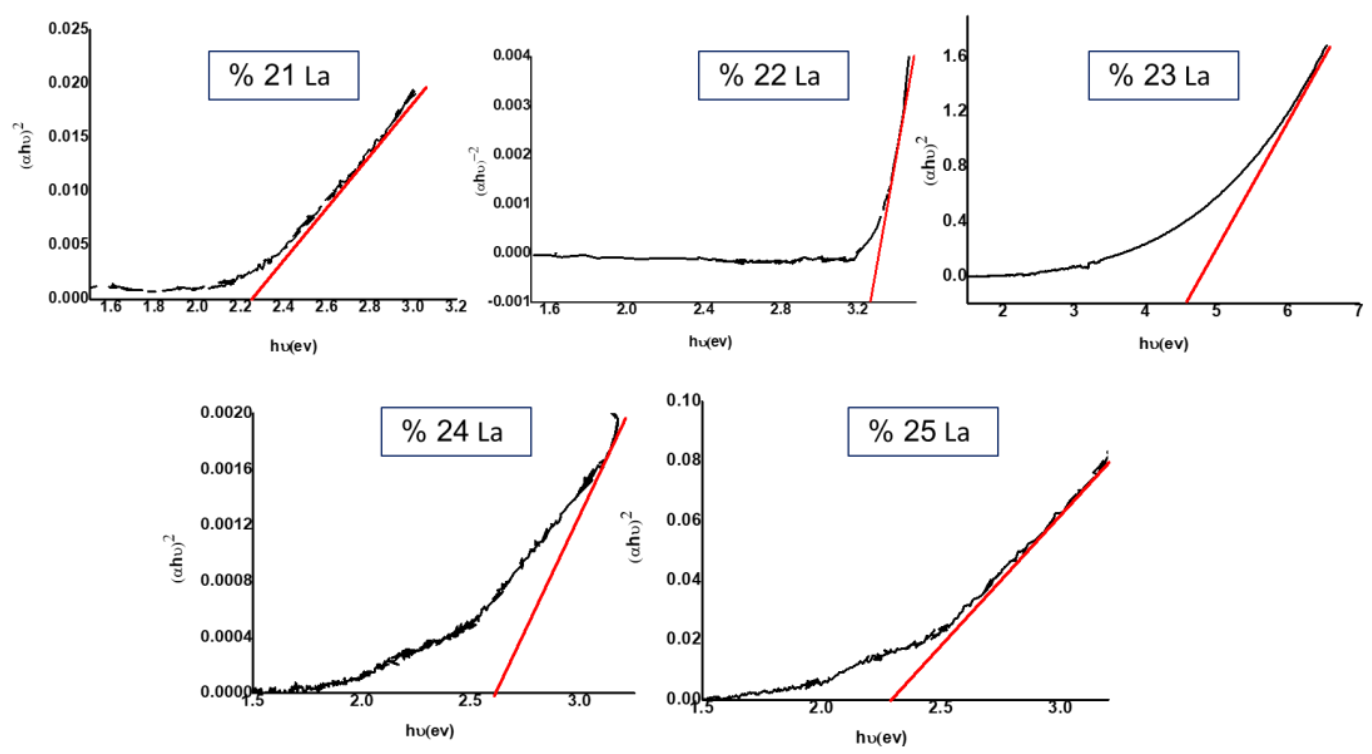

Figure 7. Energy gaps of PLT powders annealed at $1000^{\circ} \mathrm{C}$ for $4 \mathrm{~h}$. 


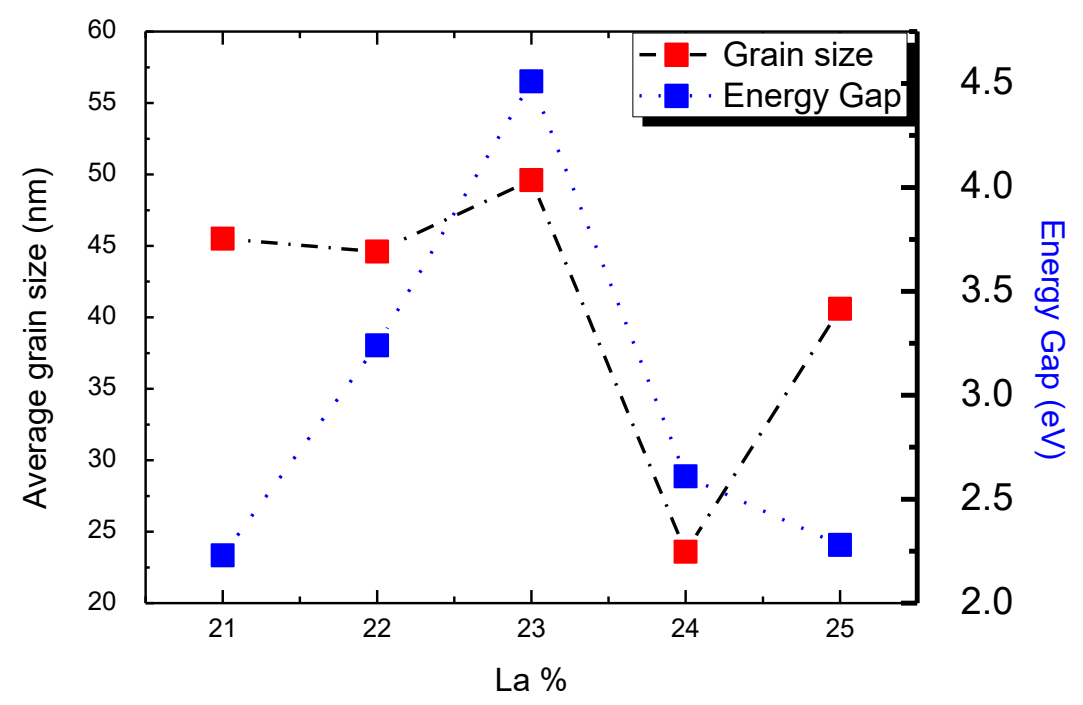

Figure 8. Crystallite sizes and energy gap of PLT powders with different La concentrations after annealing.

Average particle sizes and the energy gap, calculated by the Scherrer's equation and the Tauc plot, respectively, are presented in Figure 8 as a function of the La concentration. The sample with $23 \%$ La possessed the largest grain size $(49.6 \mathrm{~nm})$ and the highest energy gap $(4.5 \mathrm{eV})$ among all tested samples.

\subsection{Dielectric properties of PLT Nanoparticles.}

Dielectric studies of the PLT nanoparticles were carried out to analyses their response to an applied ac voltage ( 1 Volt) as a function of temperature and frequency. Figure 9 shows the dielectric constant $(\varepsilon r)$ of the PLT ceramics as a function of temperatures at the frequency of $10 \mathrm{kHz}$. $\varepsilon \mathrm{r}$ increased gradually with the rise in temperature and reached the maximum value $\varepsilon \mathrm{m}$ at a particular temperature known as the Curie Temperature Tm. $\varepsilon \mathrm{m}$ values of PLT are listed in table 1, showing that PLT with $23 \%$ La had the highest $\mathrm{\varepsilon m}$ (3649). The Curie Temperature Tc and temperature corresponding the maximum dielectric constant Tm for La-doped samples shifted towards low temperature. 


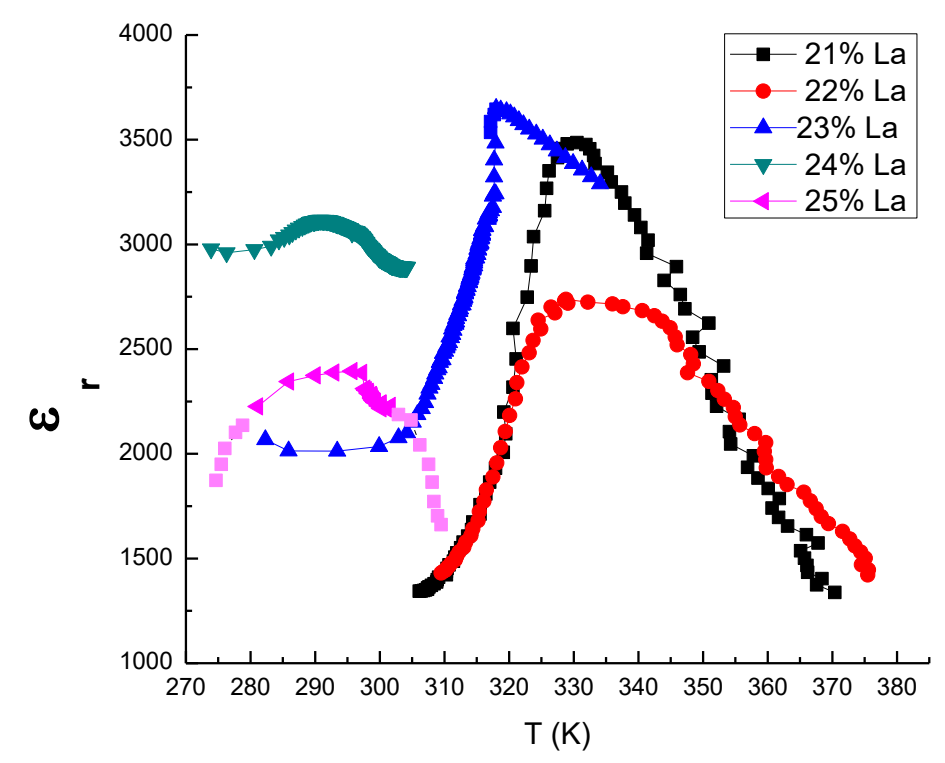

Figure 9. Temperature dependence of the dielectric constant of ( $\mathrm{Pb} 1-\mathrm{x}$ Lax $\square 0.5 \mathrm{x}) \mathrm{TiO} 3$ single phase calcined at $1000^{\circ} \mathrm{C}$, where $\mathrm{x}=0.21,0.22,0.23,0.24$, and 0.25 .

It is known that dielectric permittivity of ferroelectric materials above the Curie temperature follows the Curie-Weiss law:

$$
1 / \varepsilon r=(T-T c) / C \quad \text { where } \mathrm{T}>\mathrm{Tc}
$$

where Tc is Curie-Weiss temperature and $C$ is the Curie-Weiss constant. It is observed that in part of the paraelectric phase at a temperature higher than Tm, Tcw is the Burns Temperature. A deviation from Curie-Weiss law starting at Tcw can be seen. The parameter used to describe the degree of the deviation is defined as

$$
\Delta \mathrm{Tm}=\mathrm{Tcw}-\mathrm{Tm}
$$

The Curie constant $C$ was obtained as the slope of the curve of the inverse values of $\varepsilon \mathrm{r} v \mathrm{vs}$. temperature (Figure 10). With an increasing La-dopant amount, the value of $C$ increased. The highest $C$ value $\left(5.2 \times 10^{5} \mathrm{~K}\right)$ was measured for the $23 \%$ La sample (Table 1$)$. The $C$ value is related to the grain size and porosity of the samples. The transition temperature Tc decreases linearly with the increasing La content.

Table 1 The dielectric properties of La-doped lead titanate ceramics at $10 \mathrm{kHz}$.

\begin{tabular}{|c|c|c|c|c|c|c|c|c|c|}
\hline Sample & $\boldsymbol{\varepsilon} \mathbf{m}$ & $\begin{array}{c}\mathbf{T}_{\mathbf{m}} \\
(\mathbf{K})\end{array}$ & $\begin{array}{c}\mathbf{T}_{\mathbf{c}} \\
\mathbf{( K )}\end{array}$ & $\begin{array}{c}\mathbf{T}_{\mathbf{c w}} \\
\mathbf{( K )}\end{array}$ & $\begin{array}{c}\Delta \mathbf{T}_{\mathbf{m}} \\
\mathbf{( K )}\end{array}$ & $\boldsymbol{\gamma}$ & $\mathbf{C . 1 0}^{5} \mathbf{K}$ & $\begin{array}{c}\text { Energy } \\
\mathbf{G a p} \\
\mathbf{( e V )}\end{array}$ & $\begin{array}{c}\text { Grain } \\
\mathbf{s i z e} \\
(\mathbf{n m})\end{array}$ \\
\hline $21 \% \mathrm{La}$ & 3486 & 330 & 345 & 355 & 25 & 1.74 & 0.66 & 2.23 & 45.5 \\
\hline $22 \% \mathrm{La}$ & 2737 & 329 & 340 & 355 & 26 & 2.60 & 0.99 & 3.24 & 44.6 \\
\hline $23 \% \mathrm{La}$ & 3649 & 318 & 310 & 320 & 2 & 1.37 & 5.2 & 4.51 & 49.6 \\
\hline $24 \% \mathrm{La}$ & 3115 & 291 & 275 & 295 & 4 & 1.83 & 3.3 & 2.61 & 23.6 \\
\hline $25 \% \mathrm{La}$ & 2394 & 296 & 270 & 298 & 2 & 1.04 & 1.4 & 2.28 & 40.6 \\
\hline
\end{tabular}




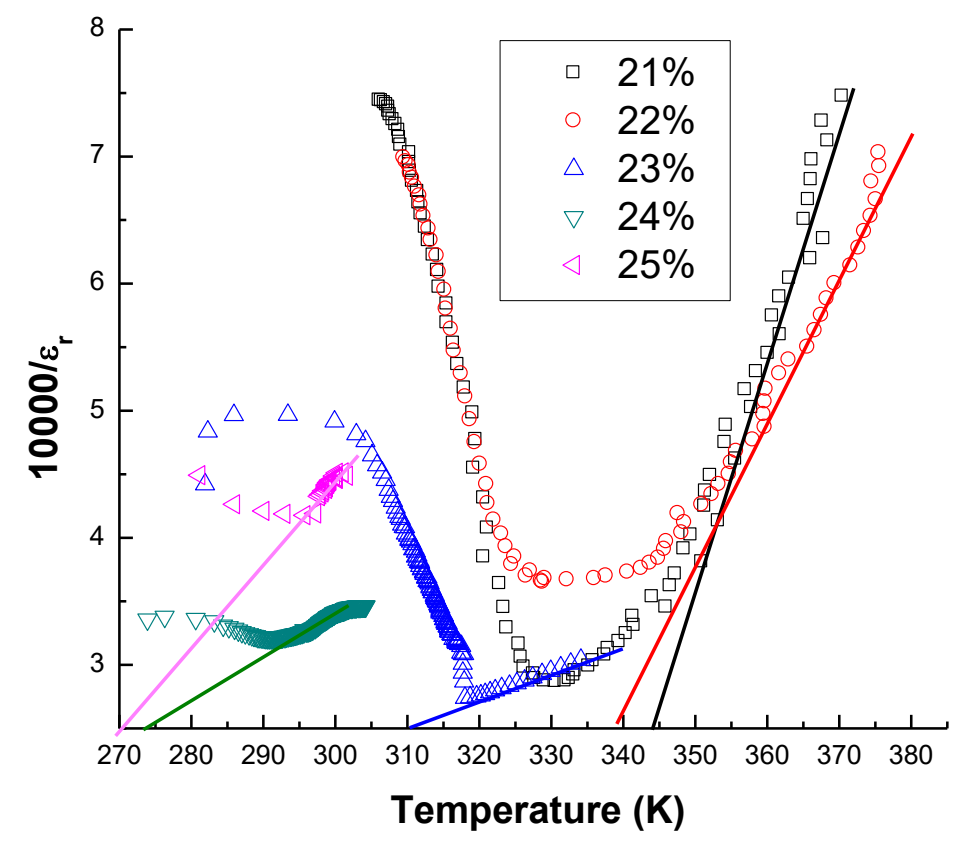

Figure 10. The inverse dielectric permittivity $(10000 / \varepsilon \mathrm{r})$ as a function of temperature at $10 \mathrm{kHz}$. (The solid lines are the fitting curves based on the Curie-Weiss law for (Pb1-x Lax $\square 0.5 \mathrm{x}) \mathrm{TiO} 3$ single phase calcined at $1000^{\circ} \mathrm{C}$, where $\mathrm{x}=0.21,0.22,0.23,0.24$, and 0.25 .)

The dielectric characteristics of the relaxor ferroelectric, different from the typical Curie-Weiss behavior, can be defined by a modified Curie-Weiss equation:

$$
1 / \varepsilon-1 / \varepsilon \mathrm{m}=(\mathrm{T}-\mathrm{Tm}) \gamma / \mathrm{C} 1,1 \leq \gamma \leq 2,
$$

where $\gamma$ and $\mathrm{C} 1$ are assumed to be constants. The parameter $\gamma$ provides information on the character of the phase transition: when $\gamma=1$ a normal Curie-Weiss law is obtained and $\gamma=2$ describes a complete diffuse phase transition [33]. 

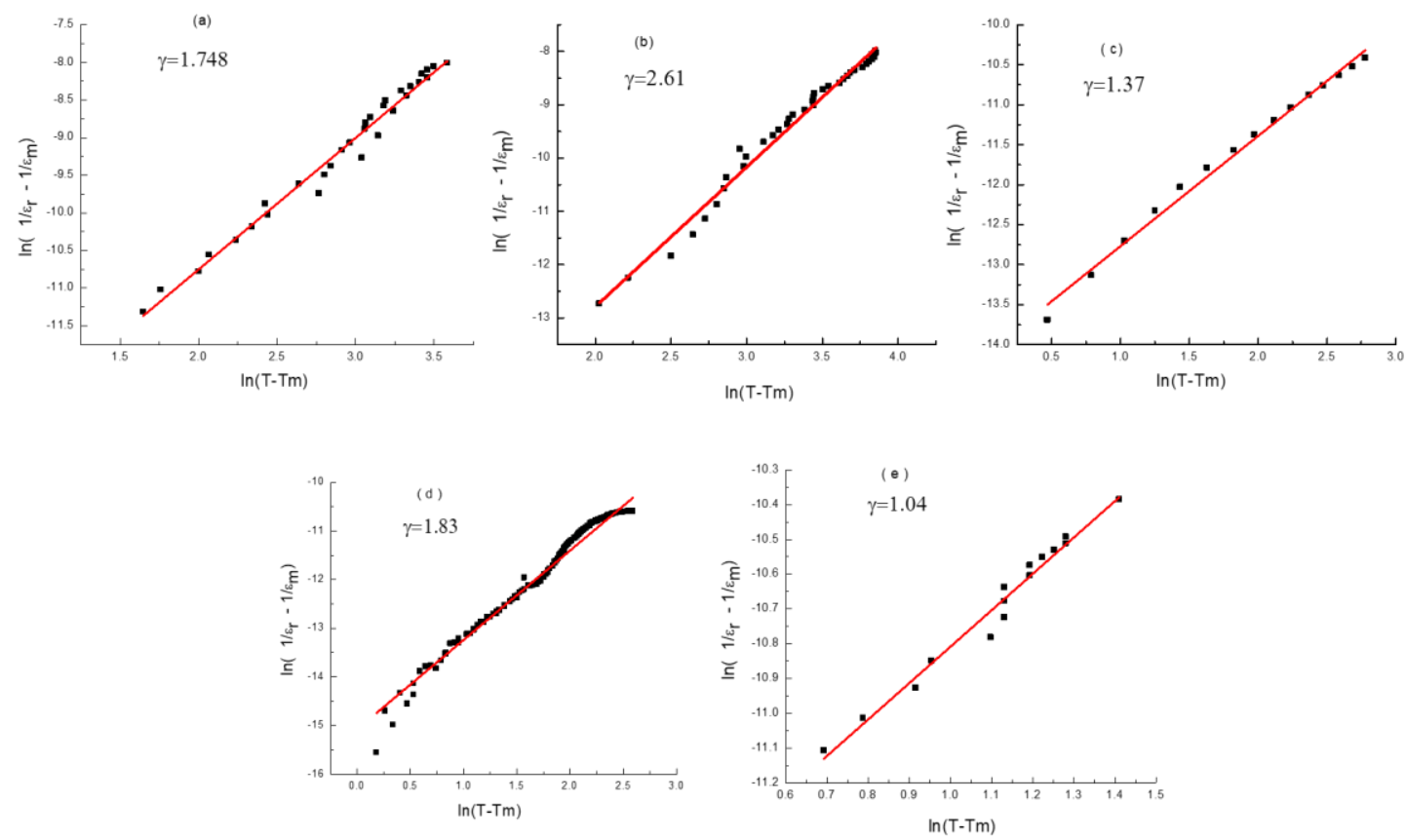

Figure 11. $\operatorname{Ln}\left(1 / \varepsilon^{-1 / \varepsilon m}\right)$ as a function of $\ln (\mathrm{T}-\mathrm{Tm})$ for different grain sizes. [Symbols: experimental data, solid line: fits to Eq. (1)].

Plots of $\ln (1 / \varepsilon-1 / \varepsilon m)$ as a function of $\ln (T-T m)$ for the tested PLT samples with deferent La concentrations are presented in Figure 11. Linear relationships are observed for all five samples. By fitting the data to Eq. (1), the critical exponent $\gamma$ representing the degree of diffuse transition was obtained as the slope of the fitting curve. At $10 \mathrm{kHz}, \gamma=1.74,2.61,1.37,1.83$, and 1.04 for PLT ceramics with La concentration of $21 \%, 22 \%, 23 \%, 24 \%$, and $25 \%$, respectively.

\section{Conclusion}

PLT nanoparticles with different La concentrations (i.e., 21\%, 22\%, 23\%, 24\%, and 25\%) have been successfully prepared by the sol-gel method with different annealing times (i.e., 2 and $4 \mathrm{~h}$ ) at the same sintering temperature of $1000{ }^{\circ} \mathrm{C}$. In general, no secondary phases have been observed for the PLT with 23\% La (PLT23) in its XRD spectrum. Structural, optical, and dielectric properties of the synthesized PLT have been studied. Sample PLT23 is distinguished from other PLT samples due to its relatively higher grain size $(\sim 49.6 \mathrm{~nm})$, energy gap $(\sim 4.5 \mathrm{eV})$, Curie-Weiss constant $(\sim 5.2 \times 105 \mathrm{~K})$, and the maximum dielectric constant ( $\sim 3649)$.

Supplementary Materials: No supplementary materials

Author Contributions: “conceptualization, M. Mostafa and G. M. Rashwan, and M. K. Gerges; methodology, M. Mostafa, G. M. Rashwan, and M. K. Gerges; software, M. Mostafa ; validation, M. Mostafa, G. M. Rashwan, and M. K. Gerges; formal analysis, M. Mostafa.; investigation, M. Mostafa; resources, M. Mostafa, Z.A. Alrowaili ; data curation, M. Mostafa ; writing - original draft preparation, M. Mostafa; writing-review and editing, M. Mostafa; visualization, M. Mostafa, Z.A. Alrowaili ; supervision, M. Mostafa; project administration, M. Mostafa ; funding acquisition, Z.A. Alrowaili"

Funding: : "This research received no external funding" 
Acknowledgments: The authors are thankful to technician members of Central laboratory, south valley university , H. Mohamed ,A.Ibrahem, N.Maghrabi,H.Barakat and F.Elrashedi for providing XRD and electron microscopic facilities.

Conflicts of Interest: "The authors declare no conflict of interest."

\section{References}

1. Kong, L. B., Zhang, T. S., Ma, J., and Boey, F. Progress in synthesis of ferroelectric ceramic materials via high-energy mechanochemical technique. Prog. Mater. Sci. 2007, 53(2), 207-322.

2. Galasso F. S., and Pyle J. Ordering in compounds of the A(B'0.33Ta0.67)O3 Type. J. Inorg. Chem. 1963, 2(3), 482-484.

3. Zhang, X., Wang Q. and Gu B. Study of the order-disorder transition in A(B'B")O3 perovskite type ceramics. J. Am. Ceram. Soc. 1991, 74 (11), 2846-2850.

4. Hiraki N., Nakamura k., Toi K., and Itoh. S., Ion temperature measurements of turbulently heated tokamak plasma by Doppler-Broadening of visible lines in TRIAM-1. Jpn. J. Appl. Phys. 1981, 20(1), 183-187.

5. Auciello O., Scott J.F., Ramesh R. The physics of ferroelectric memories. Phys. Today. 1981, 51(7), $22-27$.

6. Mendiola J., Jiménez B., Alemany C., Pardo L., and Del Olmo L. Influence of calcium on the ferroelectricity of modified lead titanate ceramics. Ferroelectrics 1989, 94(1), 183-188.

7. Jaffe B., Cook R., and Jaffe H., Piezoele. Ceramics, Academic Press, New York, 1971, 115.

8. Szafraniak I., Połomska M., and Hilczer B. XRD, TEM and Raman scattering studies of PbTiO3 nanopowders. Cryst. Res. Technol. 2006, 41(6), 576-579.

9. Wongmaneerung R., Rujiwatra A., Yimnirun R., and Ananta S. Fabrication and dielectric properties of lead titanate nanocomposites. J. Alloys Compd. 2009, 475(1-2), 473-478.

10. Szafraniak-Wiza I., Hilczer B., Talik E., Pietraszko A., and Malic B. Ferroelectric perovskite nanopowders obtained by mechanochemical synthesis. Process. Appl. Ceram. 2010, 4(3), 99-106.

11. Chankaew C. and Rujiwatra A. Hydrothermal synthesis of lead titanate fine powders at water boiling temperature. Chiang Mai J. Sci. 2010, 37(1), 92-98.

12. Lanki M., Nourmohammadi A., and Feiz M. H. A precise investigation of lead partitioning in sol-gel derived PbTiO3 nanopowders. Ferroelectrics 2013, 448(1), 123-133.

13. Ishikawa K., Okada N., Takada K., Nomura T., and Hagino M. Crystallization and growth process of lead titanate fine particles from alkoxide-prepared powders. Jpn. J. Appl. Phys. 2013, 33(6R), 3495.

14. Gerges M.K., Mostafa M., and Rashwan G. M. Structural, optical and electrical properties of PbTiO3 nanoparticles prepared by Sol-Gel method. Int. J. Res. Eng. Technol. 2013, 2 (4), 42-49.

15. Haertling G.H. Improved hot-pressed electrooptical ceramics in the (Pb, La)(Zr, Ti)O3 system. J. Am. Ceram. Soc. 1971, 54(6), 303-309

16. Takayama R., Tomita Y., Lijima K., and Ueda I. Pyroelectric linear array infrared sensors made of c-axisoriented La-modified PbTiO3 thin films. J. Appl. Phys. 1988, 63(12), 5868-5872.

17. Gamal G. A., Gerges M. K., and Massaud M.A. Influence of structure on Curie Weiss constant of [(Pb1-x Srx)1-1.5zLaz]TiO3 ceramics. Egypt. J. Solids 2007, 30(1), 103-119.

18. Kutnjak Z., Petzelt J., and Blinc R. The giant electromechanical response in ferroelectric relaxors as a critical phenomenon. Nature 2006, 441(7096), 956-959.

19. Zhang S., Jiang W., Meyer J. R. Jr., Li F., Luo J., and Cao W. Measurements of face shear properties in relaxor-PbTiO3 single crystals. J. Appl. Phys. 2011, 110(6), 064106.

20. Zhang Y., Gao G., Chan H. L.W., Dai J., Wang Y., and Hao J. Piezo-photonic effect-induced dual-mode light and ultrasound emissions from ZnS: Mn/PMN-PT thin-film structures. Adv. Mater. 2012, 24(13), 17291735.

21. Windsch W., Gerges M. K., Michel D., Schlemmbach H., Salzer A., and Reich P. Spectroscopic and dielectric studies on lanthanum modified PbTiO3 ceramics. Ferroelectrics 2012, 109(1), 119-124.

22. Gamal G. A., Gerges M. K., and Massaud M. A. Influence of structure on Curie Weiss constant of [(Pb1-x Srx)1-1.5zLaz]TiO3 ceramics. Egyptian Journal of Solids Egypt. J. Solids, 30(1), 103-119.

23. Wu L., Wei C. C., Wu T. S., and Teng C. C. Dielectric properties of modified PZT ceramics. J. Phys. C: Solid State Phys. 1983, 16(14), 2803.

24. King G. and Goo E. K. Effect of the c/a ratio on the domain structure in (Pb1-x,Cax)TiO3. J. Am. Ceram. Soc. 1990, 73(6), 1534-1539. 
25. Chan C. C., Hsieh Y. T., Yang C. F., and Cheng P. S. Sintering and dielectric properties of Sr(Bi2Ta2)1xTi4xO9 ceramics. Ceram. Int. 2003, 29(5), 495-498.

26. Swartz S. L., Shrout T. R., Schulze W. A., and Cross L. E., Dielectric properties of lead-magnesium niobite ceramics. J. Am. Ceram. Soc. 1984, 67(5), 311-314.

27. Chen M., Yao X., and Zhang L. Grain size dependence of dielectric and field-induced strain properties of chemical prepared (Pb, La)(Zn, Sn, Ti)O3 antiferroelectric ceramics. Ceram. Int. 2002, 28(2), 201-207.

28. Kang B. S. and Choi S. K. Diffuse dielectric anomaly of BaTiO3 in the temperature range of $400-700^{\circ} \mathrm{C}$. Solid State Commun. 2002, 121(8), 441-446.

29. Garcia S., Portelles J., Martinez F., Fount R., and Quinones J. R. Grain growth in polycrystalline $\mathrm{Ba} 0.5 \mathrm{Sr} 0.5 \mathrm{TiO} 3$ ceramics prepared at different sintering times. Rev. Mex. Fis. 2003, 49 (1), 15-19.

30. Szymczak L., Ujma Z., Handere J., and Kapusta J. Sintering effects on dielectric properties of (Ba,Sr)TiO3 ceramics. Ceram. Int. 2004, 30(6), 1003-1008.

31. McNeal M. P., Jang S. J., and Newnham R. E. The effect of grain and particle size on the microwave properties of barium titanate (BaTiO3). J. Appl. Phys. 2004, 83(6), 3288-3297.

32. Massaud M., Khaled., Hussien A. S., and Reham R. Effect of laser beam on structural, optical, and electrical properties of BaTiO3 nanoparticles during sol-gel preparation. J. Korean Ceram. Soc. 2018, 55(6), 581-589.

33. Tang X. G., Effect of grain size on the electrical properties of $(\mathrm{Ba}, \mathrm{Ca})(\mathrm{Zr}, \mathrm{Ti}) \mathrm{O} 3$ relaxor ferroelectric ceramics. J. Appl. Phys. 2005, 97(3), 034109. 